\title{
Wild Edible Fruits of Arunachal Pradesh, India: Ethno-Medicinal Uses, Socio Economic Importance and Role in Rural Economy and Livelihood Security
}

Tridip Hazarika ( $\nabla$ tridip28@gmail.com )

Mizoram University https://orcid.org/0000-0002-6452-8731

\section{Basik Tayeng}

Mizoram University

\section{Research}

Keywords: Arunachal Pradesh, Ethno-medicinal value, India, Socio-economic importance, Wild edible fruits

Posted Date: August 12th, 2020

DOI: https://doi.org/10.21203/rs.3.rs-51721/v2

License: (c) (i) This work is licensed under a Creative Commons Attribution 4.0 International License.

Read Full License 
The authors have withdrawn this preprint from Research Square 